\title{
Epinephrine Supports the Postabsorptive Plasma Glucose Concentration and Prevents Hypoglycemia when Glucagon Secretion Is Deficient in Man
}

\author{
Stephen G. Rosen, William E. Clutter, Michael A. Berk, \\ Suresh D. Shah, and Philip E. Cryer \\ Metabolism Division of the Department of Medicine, and the \\ General Clinical Research Center and Diabetes Research and \\ Training Center, Washington University School of Medicine, \\ St. Louis, Missouri 63110
}

bstract. We hypothesized that adrenergic mechanisms support the postabsorptive plasma glucose concentration, and prevent hypoglycemia when glucagon secretion is deficient. Accordingly, we assessed the impact of glucagon deficiency, produced by infusion of somatostatin with insulin, without and with pharmacologic $\alpha$ - and $\beta$-adrenergic blockade on the postabsorptive plasma glucose concentration and glucose kinetics in normal human subjects. During somatostatin with insulin alone mean glucose production fell from $1.5 \pm 0.05$ to $0.7 \pm 0.2 \mathrm{mg} / \mathrm{kg}$ per min and mean plasma glucose declined from $93 \pm 3$ to $67 \pm 4 \mathrm{mg} / \mathrm{dl}$ over $1 \mathrm{~h}$; glucose production then increased to base-line rates and plasma glucose plateaued at $64-67 \mathrm{mg} / \mathrm{dl}$ over $2 \mathrm{~h}$. This plateau was associated with, and is best attributed to, an eightfold increase in mean plasma epinephrine. It did not occur when adrenergic blockade was added; glucose production remained low and mean plasma glucose declined progressively to a hypoglycemic level of $45 \pm 4 \mathrm{mg} / \mathrm{dl}$, significantly $(P<0.001)$ lower than the final value during somatostatin with insulin alone. These data provide further support for the concept that maintenance of the postabsorptive plasma glucose concentration is a function of insulin and glucagon, not of insulin alone, and that adrenergic mechanisms do not normally play a critical role. They indicate, however, that an endogenous adrenergic agonist, likely adrenomedullary epinephrine, compensates for deficient glucagon secretion and prevents hypoglycemia in the

\footnotetext{
Address reprint requests to Dr. Cryer.

Received for publication 11 July 1983 and in revised form 21 October 1983.
}

J. Clin. Invest.

(c) The American Society for Clinical Investigation, Inc.

$0021-9738 / 84 / 02 / 0405 / 07 \quad \$ 1.00$

Volume 73, February 1984, 405-411 postabsorptive state in humans. Thus, postabsorptive hypoglycemia occurs when both glucagon and epinephrine are deficient, but not when either glucagon or epinephrine alone is deficient, and insulin is present.

\section{Introduction}

The physiologic mechanisms of hypoglycemic glucose counterregulation-those that promote recovery from hypoglycemia-have been defined (1-7). Glucose recovery is not due solely to dissipation of insulin. Glucagon plays a primary counterregulatory role; epinephrine compensates largely for deficient glucagon secretion. Glucose recovery fails to occur only in the absence of both glucagon and epinephrine. Although other hormonal factors, neural mechanisms, and hepatic autoregulation may be involved, they need not be invoked and are not sufficiently potent to promote recovery from hypoglycemia when the key counterregulatory hormones, glucagon and epinephrine, are deficient.

More recently it has been shown that the same principles apply to nonhypoglycemic glucose counterregulation-the physiologic mechanisms that blunt physiologic decrements in plasma glucose, prevent hypoglycemia, and restore or maintain euglycemia-in that they apply to regulation of the transition from exogenous glucose delivery to endogenous glucose production late after glucose ingestion $(8,9)$.

There is considerable evidence, reviewed by Gerich $(10,11)$, that glucagon supports postabsorptive glucose production and, therefore, the postabsorptive plasma glucose concentration. Somatostatin suppresses glucagon (and insulin) secretion and causes an initial decrease in glucose production and plasma glucose. This effect of somatostatin is prevented by glucagon replacement. Further, the small decrement in plasma glucose that follows induction of glycosuria in dogs is converted to a substantial decrement when glucagon secretion is suppressed by somatostatin (12). Despite decrements in plasma glucose, however, glucagon deficiency per se does not produce absolute hypoglycemia (10-13). On the other hand, adrenergic mechanisms do not support postabsorptive glucose production (2) in normal 
humans, and postabsorptive plasma glucose concentrations are not discernibly reduced in epinephrine-deficient (adrenalectomized) persons $(3,9)$.

Thus, maintenance of the postabsorptive plasma glucose concentration is a coordinated function of insulin and glucagon, adrenergic mechanisms do not normally play a critical role, and epinephrine compensates for deficient glucagon secretion in hypoglycemic glucose counterregulation and in at least one example of nonhypoglycemic glucose counterregulation. Therefore, we hypothesized that adrenergic mechanisms support the postabsorptive plasma glucose concentration and prevent hypoglycemia when glucagon secretion is deficient. In an initial study (13) we found that combined $\alpha$-and $\beta$-adrenergic blockade blunts the late increase in glucose production and plasma glucose that follows their initial decrease during combined insulin and glucagon deficiency produced by infusion of somatostatin. Adrenergic blockade did not, however, result in a progressive decline in plasma glucose. We reasoned that this was because insulin secretion, as well as that of glucagon, was suppressed. Therefore, we assessed the impact of glucagon deficiency produced by infusion of somatostatin with insulin, without and with pharmacologic adrenergic blockade on the postabsorptive plasma glucose concentration and glucose kinetics in normal human subjects.

\section{Methods}

10 normal human subjects (six women and four men), whose ages ranged from 18 to $33 \mathrm{yr}$ and who were within $15 \%$ of ideal body weight, gave their informed, written consent to participate in this study, which was approved by the Washington University Human Studies Committee. We performed the study at the Washington University General Clinical Research Center.

After an overnight fast, subjects assumed the supine position, which was maintained throughout. Intravenous catheters were inserted for drug/radiochemical infusions in one arm and for blood sampling in the opposite arm. A primed $(20.0 \mu \mathrm{Ci})$, continuous $(0.2 \mu \mathrm{Ci} / \mathrm{min})$ infusion of [3- $\left.{ }^{3} \mathrm{H}\right]$ glucose $(11.5 \mathrm{Ci} / \mathrm{mmol}$, New England Nuclear, Boston, MA) was begun at $-180 \mathrm{~min}$ and continued through $180 \mathrm{~min}$. Somatostatin (Beckman Instruments, Inc., Bioproducts Div., Stanford, CA) was infused in a dose of $250 \mu \mathrm{g} / \mathrm{h}$, and regular porcine insulin (Iletin II; Eli Lilly \& Co., Indianapolis, IN) was infused in a dose of $200 \mu \mathrm{U} / \mathrm{kg}$ per min, from 0 through $180 \mathrm{~min}$. On a separate occasion the same protocol was followed with addition of infusions of propranolol (Inderal; Ayerst Laboratories, New York, NY, in a dose of $0.08 \mathrm{mg} / \mathrm{min}$ after $5.0 \mathrm{mg}$ over $2 \mathrm{~min}$, and phentolamine (Regitine; Ciba-Geigy Corp., Pharmaceuticals Div., Summit, NJ), in a dose of $0.5 \mathrm{mg} / \mathrm{min}$ after $5.0 \mathrm{mg}$ over $2 \mathrm{~min}$, from -30 through $180 \mathrm{~min}$. The sequence of studies was varied randomly. Blood samples were drawn, and the blood pressure and heart rate recorded, at 10-min intervals from -60 through $180 \mathrm{~min}$.

Plasma glucose was determined with a glucose oxidase method and plasma glucose appearance and disappearance rates were calculated from the specific activities of tritiated glucose $(14,15)$. Plasma insulin $(16)$ C-peptide (17), glucagon (18), growth hormone (19), and cortisol (20) were measured by radioimmunoassay. Antiserum $30 \mathrm{~K}$ was used to measure glucagon and an antiserum purchased from Calbiochem-Behring Corp. (La Jolla, CA) to measure C-peptide. Plasma epinephrine and norepinephrine were measured with a single isotope derivative assay (21) employing 50- $\mu \mathrm{l}$ samples. Detection limits were $3.1 \mu \mathrm{U} / \mathrm{ml}$ for insulin, $1.0 \mathrm{ng} / \mathrm{ml}$ for C-peptide, $45 \mathrm{pg} / \mathrm{ml}$ for glucagon, $0.4 \mathrm{ng} / \mathrm{ml}$ for growth hormone, $3.0 \mu \mathrm{g} / \mathrm{dl}$ for cortisol, and $10 \mathrm{pg} / \mathrm{ml}$ for both epinephrine and norepinephrine. Blood alanine (22), lactate (23), glycerol (24), and $\beta$-hydroxybutyrate (24) were measured with microfluorometric enzymatic techniques.

The data (mean \pm SE) were analyzed with a $t$ test for paired data.

\section{Results}

During infusion of somatostatin with insulin the mean plasma glucose concentration declined from $93 \pm 3$ to $67 \pm 4 \mathrm{mg} / \mathrm{dl}$ at $60 \mathrm{~min}$, but then plateaued at $64-67 \mathrm{mg} / \mathrm{dl}$. The $180-\mathrm{min}$ value was $64 \pm 4 \mathrm{mg} / \mathrm{dl}$, not significantly different from the $60-\mathrm{min}$ value. The initial decline $(91 \pm 3-67 \pm 4 \mathrm{mg} / \mathrm{dl}$ at $60 \mathrm{~min})$ was similar during somatostatin with insulin coupled with propranolol plus phentolamine. However, plasma glucose did not plateau, but rather declined progressively to a 180 -min value of $45 \pm 4 \mathrm{mg} / \mathrm{dl}$, significantly $(P<0.001)$ lower than the $180-\mathrm{min}$ value of $64 \pm 4 \mathrm{mg} / \mathrm{dl}$ during somatostatin with insulin alone. The points comprising the glucose curves, illustrated in Fig. 1, were significantly different from 100 through $180 \mathrm{~min}$.

There were no consistent symptoms during somatostatin with insulin. Symptoms such as hunger and diaphoresis occurred in all subjects during somatostatin with insulin and propranolol plus phentolamine; impaired mentation, a mandatory stop point, occurred in two subjects. For data analysis the last value for each parameter from these two subjects was used in the calculation of later means.

Somatostatin with insulin resulted in an initial fall in glucose production (plasma glucose appearance rate, $R_{\mathrm{a}}$ ) from $1.5 \pm 0.05$ $\mathrm{mg} / \mathrm{kg}$ per min to a nadir of $0.7 \pm 0.2 \mathrm{mg} / \mathrm{kg}$ per min at $50 \mathrm{~min}$ (Fig. 1). Glucose production then rose to approximate basal rates from 70 through $180 \mathrm{~min}$. There were no changes in glucose utilization (plasma glucose disappearance rate, $R_{\mathrm{d}}$ ). The initial fall in glucose production (from $1.5 \pm 0.1 \mathrm{mg} / \mathrm{kg}$ per $\mathrm{min}$ to a nadir of $0.6 \pm 0.2 \mathrm{mg} / \mathrm{kg}$ per $\mathrm{min}$ at $40 \mathrm{~min}$ ) was similar during somatostatin with insulin coupled with propranolol plus phentolamine. However, the subsequent rise in glucose production was markedly attenuated; mean rates remained below base line and were significantly $(P<0.05)$ lower than during somatostatin with insulin alone by $80 \mathrm{~min}$ (Fig. 1). Again, there were no changes in glucose utilization. Thus, the progressive decline in the plasma glucose concentration was the result of reduced glucose production.

Plasma concentrations of potentially important glucoregulatory factors are also shown in Fig. 1. Plasma C-peptide, insulin, and glucagon concentrations were comparable under both study conditions. Plasma C-peptide was suppressed by $65-70 \%$ and plasma growth hormone was suppressed by $70-80 \%$, indicating the efficacy of the infused somatostatin. These represent minimum estimates of the degree of suppression since C-peptide and growth hormone levels were suppressed to levels below the sensitivity of the assays in most of the subjects. The measured 

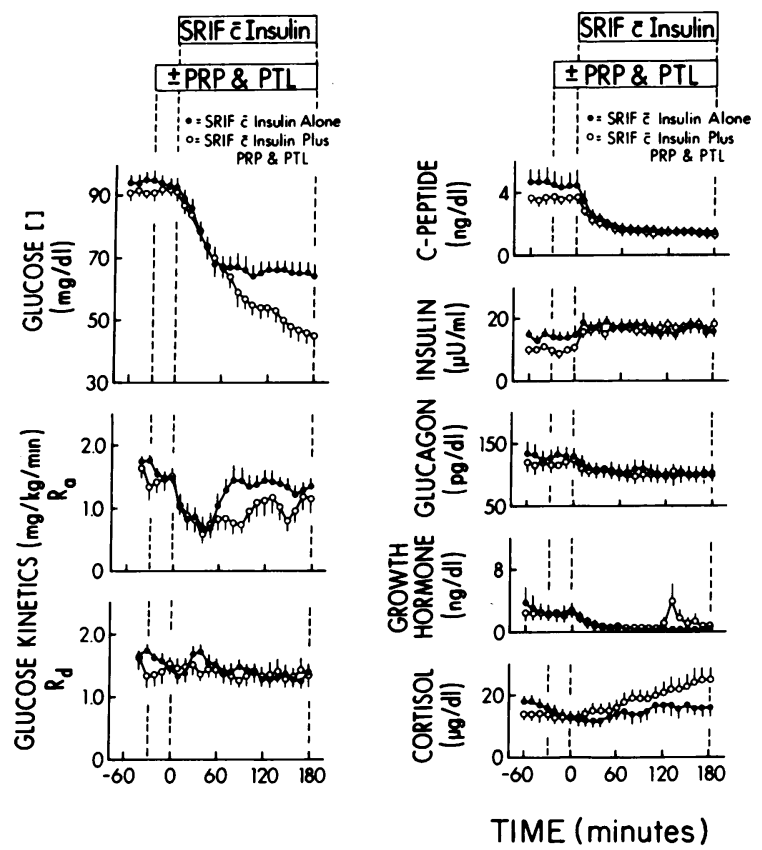

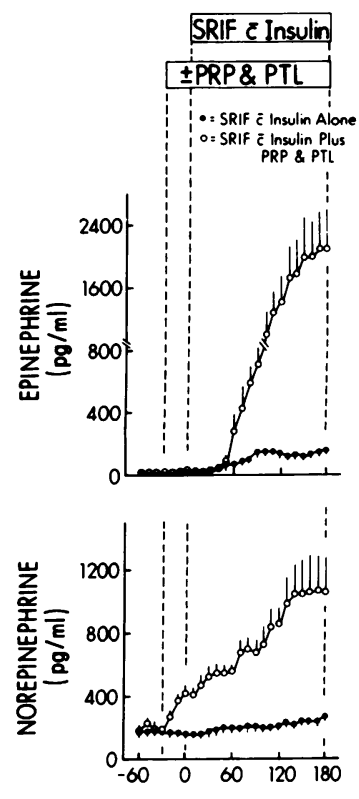

Figure 1. Mean ( $\pm \mathrm{SE})$ plasma glucose concentrations, plasma glucose appearance rates and plasma disappearance rates, and plasma concentrations of C-peptide, insulin, glucagon, growth hormone, cortisol, epinephrine, and norepinephrine during infusions of somatostatin (SRIF) with insulin alone, filled circles, and during infusions of somatostatin (SRIF) with insulin plus propranolol (PRP) and phentolamine (PTL), open circles, in 10 normal human subjects. decrements in plasma glucagon were small. However, since the antiserum used crossreacts with species in addition to 3,500dalton glucagon (25), and somatostatin suppresses 3,500-dalton glucagon preferentially (26-28), biologically active glucagon was likely suppressed substantially. The resultant of somatostatininduced suppression of insulin secretion, as evidenced by the C-peptide data, and insulin replacement, was peripheral venous insulin concentrations $\sim 20-60 \%$ above base-line values. Since the normal hepatic portal-to-peripheral venous insulin concentration ratio is $\sim 2.5: 1.0(29-32)$, this mild peripheral hyperinsulinemia must have been associated with portal hypoinsulinemia.

Plasma growth hormone concentrations were not significantly different under the two study conditions. However, increments in plasma growth hormone occurred in 3 of 10 subjects during somatostatin with insulin coupled with propranolol and phentolamine, likely a response to low plasma glucose concentrations (33) and indicating escape of growth hormone secretion from the suppressive effect of somatostatin in these three individuals. Such escape has been described previously for glucagon (34) but not, to our knowledge, for growth hormone. There was no evidence of similar escape of insulin secretion (which would not be expected since plasma glucose levels were low) from the $C$-peptide data. Further, there was no evidence of escape of glucagon secretion that, if it occurred, would have tended to raise the plasma glucose concentration and would, therefore, not explain the glucose findings.

During somatostatin with insulin coupled with propranolol plus phentolamine plasma cortisol rose to a final value of $25 \pm 4$ $\mu \mathrm{g} / \mathrm{dl}$, significantly $(P<0.01)$ higher than the corresponding value to $16 \pm 3 \mu \mathrm{g} / \mathrm{dl}$ during somatostatin with insulin alone. This was undoubtedly the result of substantially lower plasma glucose concentrations during the former study (33).

Plasma epinephrine concentrations rose more than eightfold, from $18 \pm 4$ to $153 \pm 33 \mathrm{pg} / \mathrm{ml}(P<0.01)$ at $180 \mathrm{~min}$, during somatostatin with insulin. Plasma epinephrine levels reached $150 \pm 28 \mathrm{pg} / \mathrm{ml}(P<0.001)$ at $90 \mathrm{~min}$ and remained elevated thereafter. Similar increments in epinephrine in response to similar decrements in plasma glucose have been reported previously from our laboratory (33). Plasma norepinephrine concentrations also increased, from $156 \pm 11$ to $271 \pm 29 \mathrm{pg} / \mathrm{ml}$ $(P<0.01)$, during somatostatin with insulin, although the increase was more gradual than that of epinephrine. The first value significantly higher than base line was $231 \pm 22 \mathrm{pg} / \mathrm{ml}(P$ $<0.01$ ) at $130 \mathrm{~min}$. As shown in Fig. 1, propranolol plus phentolamine did not alter plasma epinephrine concentrations significantly, but increased plasma norepinephrine levels from $171 \pm 20$ to $418 \pm 61 \mathrm{pg} / \mathrm{ml}(P<0.01)$ before initiation of somatostatin with insulin. Phentolamine is known to increase plasma norepinephrine (35), which is likely the result of increased norepinephrine release due to presynaptic $\alpha_{2}$-adrenergic receptor blockade, perhaps coupled with reflex sympathetic activation triggered by the small decrease in blood pressure produced by phentolamine (see below). Further, propranolol decreases the clearance of catecholamines from the circulation (36). Propranolol plus phentolamine markedly enhanced the plasma catecholamine responses to decrements in plasma glucose during somatostatin with insulin. Plasma epinephrine rose to a 180min value of $2,110 \pm 510 \mathrm{pg} / \mathrm{ml}$, significantly $(P<0.01)$ higher than the corresponding value of $153 \pm 33 \mathrm{pg} / \mathrm{ml}$ during soma- 
tostatin with insulin alone. Plasma norepinephrine rose to a $180-\mathrm{min}$ value of $1,060 \pm 225 \mathrm{pg} / \mathrm{ml}$, significantly $(P<0.01)$ higher than the corresponding value of $271 \pm 29 \mathrm{pg} / \mathrm{ml}$ during somatostatin with insulin alone.

Blood concentrations of metabolic intermediates are shown in Fig. 2. During somatostatin with insulin alone blood lactate rose from $770 \pm 84$ to a peak of $1,095 \pm 136 \mu \mathrm{mol} / \mathrm{liter}(P<0.02)$ at $130 \mathrm{~min}$; this rise did not occur during somatostatin with insulin coupled with propranolol plus phentolamine $(683 \pm 60$ $817 \pm 53 \mu \mathrm{mol} /$ liter). Blood alanine rose from $303 \pm 23$ to a peak of $347 \pm 29 \mu \mathrm{mol} / \mathrm{liter}(P<0.05)$ at $150 \mathrm{~min}$ during somatostatin with insulin alone and similarly, from $285 \pm 23$ to $338 \pm 23 \mu \mathrm{mol} /$ liter $(P<0.02)$ during somatostatin with insulin coupled with propranolol plus phentolamine. Blood glycerol declined from $83 \pm 6$ to a nadir of $55 \pm 7 \mu \mathrm{mol} / \mathrm{liter}(P<0.02)$ at $40 \mathrm{~min}$ and then rose to $89 \pm 21 \mu \mathrm{mol} / \mathrm{liter}$ at $160 \mathrm{~min}$ during somatostatin with insulin alone. In contrast, during somatostatin with insulin coupled with propranolol plus phentolamine, blood glycerol declined progressively from $84 \pm 9$ to $64 \pm 9 \mu \mathrm{mol} / \mathrm{liter}$ at $40 \mathrm{~min}$, to $39 \pm 5 \mu \mathrm{mol} / \mathrm{liter}$ at $160 \mathrm{~min},(P<0.05 \mathrm{vs}$. the control value of $89 \pm 21 \mu \mathrm{mol} /$ liter). Blood $\beta$-hydroxybutyrate levels declined from $128 \pm 21$ to $75 \pm 5 \mu \mathrm{mol} / \mathrm{liter}(P<0.02)$ at $60 \mathrm{~min}$ and remained at about that level thereafter during somatostatin with insulin alone; similar changes ( $114 \pm 13$ to $66 \pm 4 \mu \mathrm{mol} / \mathrm{liter}$ ) occurred during somatostatin with insulin coupled with propranolol plus phentolamine.

As shown in Table I, there were no significant changes in heart rate or blood pressure during somatostatin with insulin alone although heart rate tended to rise. During somatostatin with insulin coupled with propranolol plus phentolamine, mean heart rates, systolic blood pressures, and diastolic blood pressures were significantly lower than those during somatostatin with insulin alone.
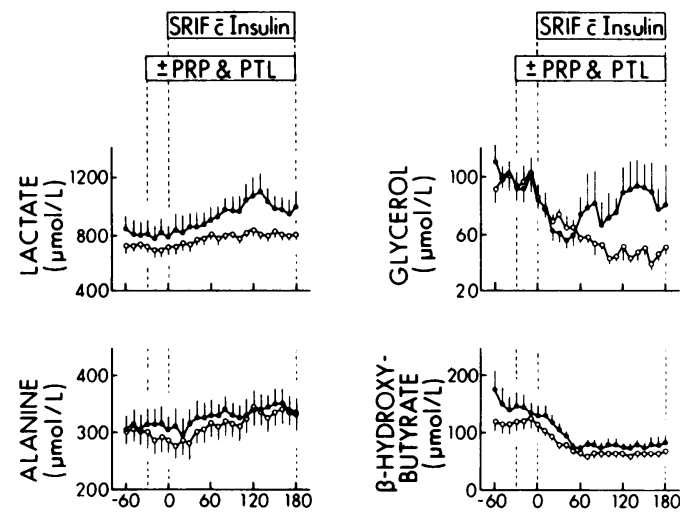

TIME (minutes)

Figure 2. Mean ( \pm SE) blood lactate, alanine, glycerol, and $\beta$-hydroxybutyrate concentrations during infusions of somatostatin (SRIF) with insulin alone, filled circles, and during infusions of somatostatin (SRIF) with insulin plus propranolol (PRP) and phentolamine (PTL), open circles, in 10 normal human subjects.

\section{Discussion}

These data document that adrenergic mechanisms, likely mediated by adrenomedullary epinephrine, support the postabsorptive plasma glucose concentration, and prevent hypoglycemia, when glucagon secretion is suppressed, insulin is present, and plasma glucose levels are lowered in normal human subjects.

There is considerable evidence that glucagon normally supports postabsorptive glucose production and functions in concert with insulin to maintain the postabsorptive plasma glucose concentration $(10,11,13)$. The present studies were not designed to reassess this concept, but the findings are consistent with it. The dose of insulin $(200 \mu \mathrm{U} / \mathrm{kg}$ per min) that we infused with somatostatin was a compromise. Ideally, we would have wished to produce isolated glucagon deficiency by infusing somatostatin with insulin in a dose sufficient to maintain portal insulin concentrations at base-line levels. That is, of course, impractical with peripheral venous infusions. Thus, we selected an insulin dose that, when infused with somatostatin, produced mild peripheral venous hyperinsulinemia and portal venous insulin levels that can be estimated (from the measured peripheral insulin levels at base line and during infusions and from the degree of C-peptide suppression) to be approximately twothirds of base-line levels. Nonetheless, the initial decrease in glucose production and plasma glucose, with no increase in glucose utilization, provide biologic evidence of isolated glucagon deficiency. Thus, we produced greater initial decrements in plasma glucose than did Saccà et al. (37) despite the fact that they infused larger doses of insulin and did not suppress endogenous insulin (or glucagon) secretion and thus produced peripheral venous insulin levels $\sim 25 \%$ higher (the difference in portal venous insulin levels may well have been greater) than those in the present study. Nonetheless, the latter data clearly underscore the fact that moderate hyperinsulinemia can result in decrements in plasma glucose despite normal glucagon secretion. Since such glucose decrements do not result in hypoglycemia (37), effective glucose counterregulatory systems must be operative. The present data indicate that these include epinephrine as well as glucagon and that other hormonal, neural, or autoregulatory mechanisms need not be invoked.

After an initial decrease, glucose production rose to approximate basal rates and mean plasma glucose plateaued at 64-67 mg/dl over $2 \mathrm{~h}$ despite ongoing suppression of glucagon secretion. Thus, a factor in addition to glucagon must support the postabsorptive plasma glucose concentration, at least when glucagon secretion is deficient and plasma glucose levels are lowered. The finding of temporally related increments in plasma epinephrine suggests that that factor is an adrenomedullary discharge. This suggestion is supported by the results of the study with pharmacologic adrenergic blockade.

The plateau of plasma glucose that occurred during glucagon deficiency produced by somatostatin with insulin did not occur when glucagon deficiency was produced during combined $\alpha$ and $\beta$-adrenergic blockade with propranolol and phentolamine. 
Table I. Mean $( \pm S E)$ Heart Rates and Blood Pressures during Somatostatin with Insulin and Somatostatin with Insulin Plus Propranolol and Phentolamine

\begin{tabular}{|c|c|c|c|c|c|c|}
\hline & \multicolumn{6}{|c|}{ Time (minutes) } \\
\hline & -60 & $-30^{*}$ & $0 \neq$ & 60 & 120 & 180 \\
\hline \multicolumn{7}{|l|}{ Heart rate (beats/min) } \\
\hline SRIF $\bar{c}$ insulin & $63 \pm 4$ & $58 \pm 3$ & $57 \pm 3$ & $60 \pm 3$ & $62 \pm 2$ & $62 \pm 3$ \\
\hline SRIF c̄ insulin plus PRP and PTL & $59 \pm 2$ & $59 \pm 3$ & $58 \pm 3$ & $58 \pm 3$ & $57 \pm 3$ & $56 \pm 2$ \\
\hline$P$ & NS & NS & NS & NS & $<0.01$ & $<0.05$ \\
\hline \multicolumn{7}{|l|}{ Systolic blood pressure $(\mathrm{mmHg})$} \\
\hline SRIF $\bar{c}$ insulin & $108 \pm 3$ & $110 \pm 3$ & $109 \pm 3$ & $110 \pm 3$ & $107 \pm 3$ & $109 \pm 4$ \\
\hline SRIF c̄ insulin plus PRP and PTL & $107 \pm 3$ & $109 \pm 4$ & $94 \pm 4$ & $93 \pm 4$ & $89 \pm 5$ & $88 \pm 5$ \\
\hline$P$ & NS & NS & $<0.01$ & $<0.001$ & $<0.001$ & $<0.001$ \\
\hline \multicolumn{7}{|l|}{ Diastolic blood pressure $(\mathrm{mmHg})$} \\
\hline SRIF $\bar{c}$ insulin & $68 \pm 1$ & $69 \pm 2$ & $72 \pm 2$ & $71 \pm 2$ & $69 \pm 2$ & $69 \pm 2$ \\
\hline SRIF $\bar{c}$ insulin plus PRP and PTL & $68 \pm 2$ & $68 \pm 2$ & $68 \pm 2$ & $65 \pm 3$ & $63 \pm 3$ & $62 \pm 3$ \\
\hline$P$ & NS & NS & NS & $<0.05$ & $<0.05$ & $<0.05$ \\
\hline
\end{tabular}

SRIF, somatostatin; PRP, propranolol; PTL, phentolamine; NS, not significant. * Propranolol and phentolamine started. ‡ Somatostatin with insulin started.

Rather, mean plasma glucose declined progressively to a hypoglycemic level, $45 \mathrm{mg} / \mathrm{dl}$. This decline was the result of reduced glucose production. Insulin and glucagon levels were comparable during both studies. Thus, adrenergic mechanisms support postabsorptive glucose production and the plasma glucose concentration, and prevent hypoglycemia, when glucagon secretion is deficient.

Although these adrenergic mechanisms could be activated by norepinephrine released from sympathetic nerves, it is far more likely that they are activated by adrenomedullary epinephrine for three reasons. First, the plasma glucose plateau during somatostatin with insulin alone was temporally associated with a more than eightfold increase in mean plasma epinephrine to a level known to have hyperglycemic effects in man (38). In contrast, the increment in plasma norepinephrine was small and occurred considerably later. Second, in both hypoglycemic glucose counterregulation (1-7) and in another model of nonhypoglycemic glucose counterregulation (9), adrenomedullary epinephrine, but not sympathetic neural norepinephrine, compensates for deficient glucagon secretion. Third, measurements of sympathetic activity by means of tissue norepinephrine turnover in rats $(39,40)$ have shown that hypoglycemia suppresses, rather than stimulates, the activity of the sympathetic nervous system. Insulin-induced hypoglycemia fails to produce an increase in plasma norepinephrine in persons who have undergone bilateral adrenalectomy (3), indicating that the small increment seen in normal subjects is the result of norepinephrine release from the adrenal medullae rather than from sympathetic nerves. Thus, it is adrenomedullary epinephrine, rather than sympathetic neural norepinephrine, that supports the postabsorptive plasma glucose concentration when glucagon is deficient. The kinetic data indicate that this is largely the result of an epinephrineinduced increase in glucose production. However, epinephrine is known to both stimulate glucose production and limit glucose utilization (41). The present data do not exclude an additional effect of epinephrine on glucose utilization during glucagon deficiency.

Increments in blood lactate and blood glycerol, indices of glycolysis and lipolysis, respectively, occurred during glucagon deficiency. These changes were prevented by combined adrenergic blockade and provide further evidence of biologically active epinephrine release in response to the plasma glucose decrements produced by glucagon deficiency.

In summary, maintenance of the postabsorptive plasma glucose concentration is a coordinated function of insulin and glucagon, not of insulin alone, in man. Adrenergic mechanisms do not normally play a critical role. However, epinephrine compensates for deficient glucagon secretion and prevents hypoglycemia. Thus, postabsorptive hypoglycemia occurs when both glucagon secretion and epinephrine are deficient and insulin is present. Although other hormonal, neural, or autoregulatory counterregulatory factors may be involved in maintenance of the postabsorptive plasma glucose concentration, they need not be invoked and they are not sufficiently potent to prevent postabsorptive hypoglycemia when the key glucose counterregulatory hormones, glucagon and epinephrine, are deficient.

This synthesis should not be interpreted to suggest that the counterregulatory function of epinephrine is limited to glucagondeficient states. It is quite conceivable that epinephrine prevents hypoglycemia when sustained hyperinsulinemia or other glucose- 
lowering factors are sufficient to overcome the counterregulatory actions of glucagon and result in a decrement in plasma glucose. We would suggest, as an operational model, that small fluctuations in plasma glucose are regularly modulated by insulin and glucagon, whereas more substantial decrements in plasma glucose, regardless of their initiating mechanism, elicit adrenomedullary secretion and that epinephrine in concert with glucagon blunts the glucose decrements and prevents hypoglycemia.

These data indicate that maintenance of a level of plasma glucose adequate for normal cerebral function, and thus essential for survival, is accomplished by redundant defenses against hypoglycemia. Postabsorptive hypoglycemia does not occur during deficiency of either glucagon $(10,11$, present data) or epinephrine $(2,3,9,13)$ alone, nor during combined deficiency of glucagon and epinephrine when insulin secretion is also suppressed (13). Hypoglycemia due to glucoregulatory abnormalities occurs only when both glucagon and epinephrine are deficient and insulin is present or insulin levels are high enough to overwhelm counterregulatory mechanisms. The presence of redundant defenses against the development of postabsorptive hypoglycemia accounts for the ability of many insulin-treated patients with insulin-dependent diabetes mellitus to maintain their plasma glucose at levels sufficient for normal cerebral function despite hyperinsulinemia and deficient glucagon responses, as well as the susceptibility to hypoglycemia of those patients in whom epinephrine secretion is also deficient (7).

Thus, the principles of hypoglycemic glucose counterregulation (1-7) and those of nonhypoglycemic glucose counterregulation in both the postprandial $(8,9)$ and the postabsorptive states are fundamentally the same. Counterregulation is not due solely to dissipation of insulin. Glucagon plays a primary counterregulatory role, whereas epinephrine compensates largely for deficient glucagon secretion; epinephrine may also compensate for insufficient glucagon action. Counterregulation fails, and hypoglycemia occurs, when both glucagon and epinephrine are deficient and insulin is present.

\section{Acknowledgments}

The authors acknowledge the technical assistance of Ms. Eva Sorenson, Mr. Krishan Jethi, Ms. Denise Nachowiak, Ms. Joy Brothers, and Ms. Bakula Trivedi, the secretarial assistance of Ms. Theresa Lautner, and the assistance of the nursing staff of the Washington University General Clinical Research Center.

This work was supported by U. S. Public Health Service grants AM27085, AM20579, and RR00036.

\section{References}

1. Garber, A. J., P. E. Cryer, J. V. Santiago, M. W. Haymond, A. S. Pagliara, and D. M. Kipnis. 1976. The role of adrenergic mechanisms in the substrate and hormonal response to insulin-induced hypoglycemia in man. J. Clin. Invest. 58:7-15.

2. Clarke, W. L., J. V. Santiago, L. Thomas, M. W. Haymond, E.
Ben-Galim, and P. E. Cryer. 1979. Adrenergic mechanisms in recovery from hypoglycemia in man: adrenergic blockade. Am. J. Physiol. 236:E147-E152.

3. Gerich, J., J. Davis, M. Lorenzi, R. Rizza, N. Bohannon, J. Karam, S. Lewis, S. Kaplan, T. Schultz, and P. E. Cryer. 1979. Hormonal mechanisms of recovery from insulin-induced hypoglycemia in man. Am. J. Physiol. 236:E380-E385.

4. Rizza, R. A., P. E. Cryer, and J. E. Gerich. 1979. Role of glucagon, epinephrine and growth hormone in human glucose counter-regulation: effects of somatostatin and adrenergic blockade on plasma glucose recovery and glucose flux rates following insulin-induced hypoglycemia. J. Clin. Invest. 64:62-71.

5. Cryer, P. E. 1981. Glucose counterregulation in man. Diabetes. 30:261-264.

6. Popp, D. A., S. D. Shah, and P. E. Cryer. 1982. The role of epinephrine mediated $\beta$-adrenergic mechanisms in hypoglycemic glucose counterregulation and posthypoglycemic hyperglycemia in insulin dependent diabetes mellitus. J. Clin. Invest. 69:315-326.

7. White, N. H., D. Skor, P. E. Cryer, D. M. Bier, L. Levandowski, and J. V. Santiago. 1983. Identification of type 1 diabetic patients at increased risk for hypoglycemia during intensive therapy. N. Engl. J. Med. 308:485-491.

8. Tse, T. F., W. E. Clutter, S. D. Shah, J. P. Miller, and P. E. Cryer. 1983. Neuroendocrine responses to glucose ingestion in man: specificity, temporal relationships and quantitative aspects. J. Clin. Invest. 72:270277.

9. Tse, T. F., W. E. Clutter, S. D. Shah, and P. E. Cryer. 1983. The mechanisms of postprandial glucose counterregulation in man: physiologic roles of glucagon and epinephrine vis-a-vis insulin in the prevention of hypoglycemia late after glucose ingestion. J. Clin. Invest. 72:278286. 666.

10. Gerich, J. E. Somatostatin. 1977. Arch. Intern. Med. 137:659-

11. Gerich, J. E. 1981. Somatostatin and diabetes. Am. J. Med. 70:619-626.

12. Gauthier, C., M. Vranic, and G. Hetenyi, Jr. 1980. Importance of glucagon in regulatory rather than emergency responses to hypoglycemia. Am. J. Physiol. 238:E131-E140.

13. Rosen, S. G., W. E. Clutter, S. D. Shah, J. P. Miller, D. M. Bier, and P. E. Cryer. 1983. Direct, $\alpha$-adrenergic stimulation of hepatic glucose production in postabsorptive human subjects. Am. J. Physiol. 245:E616E626.

14. DeBodo, R. C., R. Steele, N. Altszuler, A. Dunn, and J. S. Bishop. 1963. On the hormonal regulation of carbohydrate metabolism: studies with $\mathrm{C}^{14}$ glucose. Recent Prog. Horm. Res. 19:445-488.

15. Radziuk, J., K. Norwich, and M. Vranic. 1974. Measurement and validation of nonsteady state turnover rates with applications to the insulin and glucose system. Fed. Proc. 33:1841-1864.

16. Hales, C., and P. Randle. 1963. Immunoassay of insulin with insulin antibody precipitate. Biochem. J. 88:137-146.

17. Kuzuya, H., P. M. Blix, D. L. Horwitz, D. F. Steiner, and A. H. Rubenstein. 1977. Determination of free and total insulin and C-peptide in insulin treated diabetics. Diabetes. 26:22-29.

18. Leichter, S. A., A. Pagliara, M. Greider, S. Pohl, J. Rosai, and D. M. Kipnis. 1975. Uncontrolled diabetes mellitus and hyperglucagonemia associated with an islet cell carcinoma. Am. J. Med. 58:285293.

19. Schalch, D., and M. Parker. 1964. A sensitive double antibody radioimmunoassay for growth hormone in plasma. Nature (Lond.). 203:1141-1142. 
20. Farmer, R. W., and C. E. Pierce. 1974. Plasma cortisol determination: radioimmunoassay and competitive binding compared. Clin. Chem. 20:411-414.

21. Cryer, P. E., J. V. Santiago, and S. D. Shah. 1974. Measurement of norepinephrine and epinephrine in small volumes of human plasma by a single isotope derivative method: response to the upright position. J. Clin. Endocrinol. Metab. 39:1025-1029.

22. Cahill, G. F., Jr., M. G. Herrera, A. P. Morgan, J. S. Soeldner, J. Steinke, P. Levy, G. A. Rerchand, Jr., and D. M. Kipnis. 1966. Hormone-fuel interrelationships during fasting. J. Clin. Invest. 45:17511769.

23. Lowry, O. H., J. V. Passoneau, F. X. Hasselberger, and D. V. Schultz. 1964. Effect of ischemia on known substrates and co-factors of the glycolytic pathway of the brain. J. Biol. Chem. 239:18-30.

24. Pinter, J. K., J. A. Hayaski, and J. A. Watson. 1967. Enzymatic assay of glycerol, dihydroxyacetone and glyceraldehyde. Arch. Biochem. Biophys. 121:404-414.

25. von Schenck, H., and A. O. Grubb. 1982. Interference of immunoglobulins in two glucagon radioimmunoassays. Clin. Chem. 28:1103-1107.

26. Valverde, I., R. Dobbs, and R. H. Unger. 1975. Heterogeneity of plasma glucagon immunoreactivity in normal, depancreatectomized and alloxan diabetic dogs. Metab. Clin. Exp. 24:1021-1028.

27. Jaspan, J. B., K. S. Polonsky, M. Lewis, J. Pensler, W. Pugh, A. R. Moosa, and A. H. Rubenstein. 1981. Hepatic metabolism of glucagon in the dog: contribution of the liver to overall metabolic disposal of glucagon. Am. J. Physiol. 240:E233-E244.

28. Stacpoole, P. W., J. Jaspan, A. G. Kasselberg, S. A. Halter, K. Polonsky, F. W. Gluck, J. E. Liljenquist, and D. Rabin. 1981. A familial glucagonoma syndrome. Am. J. Med. 70:1017-1026.

29. Felig, P., R. Gusberg, R. Hendler, F. E. Gump, and J. M. Kinney. 1974. Concentrations of glucagon and the insulin:glucagon ratio in the portal and peripheral circulation. Proc. Soc. Exp. Biol. Med. 147:8890.

30. Dencker, H., P. Hedner, J. Holst, and H.-G. Tranberg. 1975. Pancreatic glucagon response to an ordinary meal. Scand. J. Gastroenterol. 10:471-474.

31. Walter, R. M., Jr., E. M. Gold, C. A. Michas, and J. W. Ensinck. 1980. Portal and peripheral vein concentrations of insulin and glucagon after arginine infusion in morbidly obese subjects. Metab. Clin. Exp. 29:1037-1040.

32. Horwitz, D. L., J. I. Starr, M. E. Mako, W. G. Blackard, and A. H. Rubenstein. 1975. Proinsulin, insulin and C-peptide concentrations in human portal and peripheral blood. J. Clin. Invest. 55:1278-1283.

33. Santiago, J. V., W. L. Clarke, S. D. Shah, and P. E. Cryer. 1980. Epinephrine, norepinephrine, glucagon and growth hormone release in association with physiologic decrements in the plasma glucose concentration in normal and diabetic man. J. Clin. Endocrinol. Metab. 51:877883.

34. Polonsky, K., J. Jaspan, W. Pugh, J. Dhorajiwala, M. Abraham, P. Blix, and A. R. Moosa. 1981. Insulin and glucagon breakthrough of somatostatin suppression. Diabetes. 30:664-669.

35. Cryer, P. E., M. W. Haymond, J. V. Santiago, and S. D. Shah. 1976. Norepinephrine and epinephrine release and adrenergic mediation of smoking-associated hemodynamic and metabolic events. $N$. Engl. J. Med. 295:573-577.

36. Cryer, P. E., R. A. Rizza, M. W. Haymond, and J. E. Gerich 1980. Epinephrine and norepinephrine are cleared through beta-adrenergic, but not alpha-adrenergic, mechanisms in man. Metab. Clin. Exp. 29:1114-1117.

37. Saccà, L., R. Sherwin, R. Hendler, and P. Felig. 1979. Influence of continuous physiologic hyperinsulinemia on glucose kinetics and counterregulatory hormones in normal and diabetic humans. J. Clin. Invest. 63:849-857.

38. Clutter, W. E., D. M. Bier, S. D. Shah, and P. E. Cryer. 1980 Epinephrine plasma metabolic clearance rates and physiologic thresholds for metabolic and hemodynamic actions in man. J. Clin. Invest. 66:94101.

39. Young, J. B., and L. Landsberg. 1979. Sympathoadrenal activity in fasting pregnant rats: dissociation of adrenal medullary and sympathetic nervous system responses. J. Clin. Invest. 64:109-116.

40. Landsberg, L., L. Greff, S. Gunn, and J. B. Young. 1980. Adrenergic mechanisms in the metabolic adaptation to fasting and feeding: effects of phlorizin on diet-induced changes in sympathoadrenal activity in the rat. Metab. Clin. Exp. 29:1128-1137.

41. Rizza, R. A., M. W. Haymond, P. E. Cryer, and J. E. Gerich. 1979. Differential effects of physiologic concentrations of epinephrine on glucose production and disposal in man. Am. J. Physiol. 237:E356E362. 